\title{
Primary Cutaneous Extranodal NK/T Cell Lymphoma (Nasal Type): A Case Report and Review of Literatures
}

\author{
Wang Lijie, Jiang Feng, Zhao Qian, Jin Hui, Bai Jie, Liu Yang, Bo Kaiping, Chen Ruijuan, Liu Qin yue, Wu Jingjing, Zhang Ziyan, \\ Zhu Hanghang, Mao Xin, Song Xudong, Dong Liru, Luo Dan, and Yang Jie*
}

Affiliated Hospital of North China University of Science and Technology, Tangshan, 063000, China

*Corresponding authors: Yang Jie, Affiliated Hospital of North China University of Science and Technology, Tangshan, 063000, China, E-mail: yangjj1971@126.com

Received: 11 Oct, 2021 | Accepted: 15 Nov, 2021 | Published: 22 Nov, 2021

Citation: Lijie W, Feng J, Qian Z, Hui J, Jie B, et al. (2021) Primary Cutaneous Extranodal NK/T Cell Lymphoma (Nasal Type): A Case Report and Review of Literatures. J Clin Case Stu 6(6): dx.doi.org/10.16966/2471-4925.240

Copyright: (C) 2021 Lijie W, et al. This is an open-access article distributed under the terms of the Creative Commons Attribution License, which permits unrestricted use, distribution, and reproduction in any medium, provided the original author and source are credited.

\section{Abstract}

A case of extranodal NK/T cell lymphoma (nasal type) with skin lesion as the first manifestation is reported. A 82 year old female presented with fever for 10 days, and mass with ulceration on right shoulder for 4 days. Clinically, a walnut-sized red mass with local ulceration and scab can be seen on the right shoulder. Part of the lesion had rupture scab. A circular-like infiltrated dark red plaque with a diameter of about $4 \mathrm{~cm}$ can be seen on the right chest, with yellow and white dry secretion in the center. Multiple patches of dark red spots from coins to walnuts can be seen on the trunk and limbs. Based on skin lesions, histological, immunohistochemical staining and EBER in situ hybridization, a diagnose of primary cutaneous extranodal $\mathrm{NK} / \mathrm{T}$ cell lymphoma, nasal type was made.

Keywords: Extranodal NK/T cell lymphoma; Nasal type; Skin lesion; Primary

\section{Case Report}

A 82-year-old female was first hospitalized with fever and mass with ulceration on right shoulder. The patient developed fever with decreased appetite 10 days ago without obvious cause. During this period, the highest temperature is $39.9^{\circ} \mathrm{C}$, 4 days ago, a $1.5 \mathrm{~cm}$ diameter mass was found on the right shoulder, accompanied by redness, heat and pain, swelling. A dark red infiltrating plaque, approximately $1 \mathrm{~cm}$ in diameter, is seen on the inside of the right breast. No cough or sputum was noticed in the course of the disease. Since there is no improvement after anti-infection treatment, skin biopsy was performed for patients to make a definite diagnosis. While waiting for the examination results, the treatment plan was intravenous injection of methylprednisolone sodium succinate every day. The final diagnosis was "primary cutaneous extranodal NK/T cell lymphoma (nasal type)" by histopathology and immunohistochemistry. After that, the patient was transferred to oncology department for chemotherapy. Since its onset, it has been accompanied by fever and emaciation, without midfacial symptoms. The patient had a present history of brain infarction.

Physical examination showed that the patient's vital signs were stable, no abnormalities were found in the nose and mouth, her left limb movement was limited, and his right mouth was skewed.

Dermatological examination showed that a walnut-sized red mass can be seen on the right shoulder (Figure 1). Part of the lesion had rupture scab. A circular-like infiltrated dark red plaque with a diameter of about $4 \mathrm{~cm}$ can be seen on the right chest, with yellow and white dry secretion in the center (Figure 2). Multiple patches of dark red spots from coins to walnuts can be seen on the trunk and limbs (Figure 3).

Laboratory and auxiliary examination was as follows: blood routine: RBC $3.43 \times 10^{12} / \mathrm{L}$, HB $88 \mathrm{~g}$, WBC $0.9 \times 10^{9} / \mathrm{L}$, PLT $89 \times 10^{9} / \mathrm{L}$; coagulation series: plasma fibrinogen 1.26L. Lactate dehydrogenase 507U/L. Chest CT revealed inflammatory lesions in the lower lobes of both lungs. No obvious abnormalities was shown in rheumatism series, antinuclear antibody series and titer, superficial lymph node ultrasonography, abdominal ultrasound, brain, upper and lower abdomen and pelvic CT plain scan. Bone marrow routine indicated poor maturation of granulocytes, increased erythroids, and poor megakaryocyte production with iron deficiency.

Histopathological and immunohistochemical results of the skin lesion of the right shoulder: the tumor was comprised of lymphocyte with distinct atypia. Transparent cells, necrosis and mitosis can be seen in the tumor (Figures 4-6). Immunohistochemical staining revealed positivity for CD2, CD3, CD7, CD43, CD56 (Figure 7), TiA-1 (Figure 8), granase B (Figure 9) and vimentin. Immunohistochemistry revealed CD68 and lysozyme positivity in histiocytics. Some cells revealed positivity for CD20 (Figure 10), and a few cells revealed positivity for CD4, CD8. Immunohistochemistry demonstrated negative staining for CD30 (Figure 11). Ki67 index is 80\% (Figure 12). Epstein barr virus in situ hybridization was positive (Figure 13). 


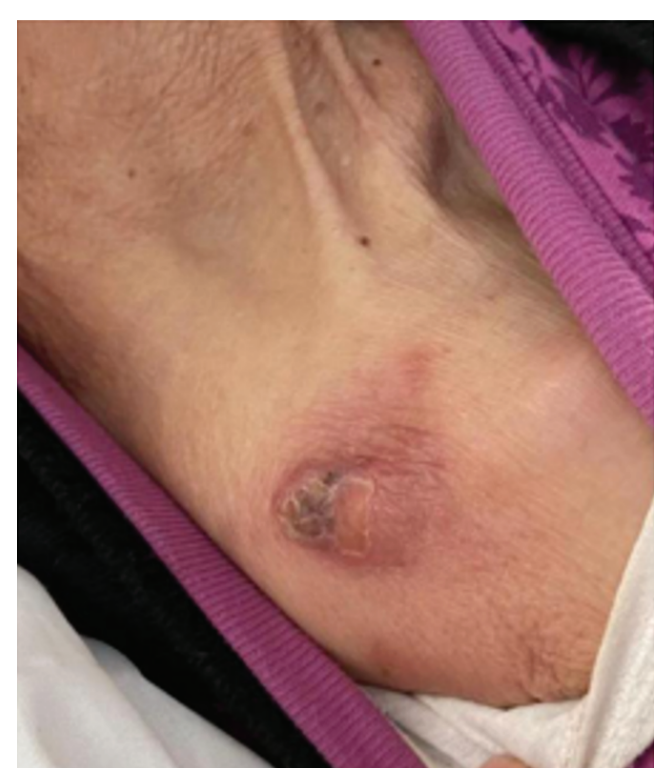

Figure 1: Awalnut-sized red mass can be seen on the right shoulder part of the lesion had rupture scab.

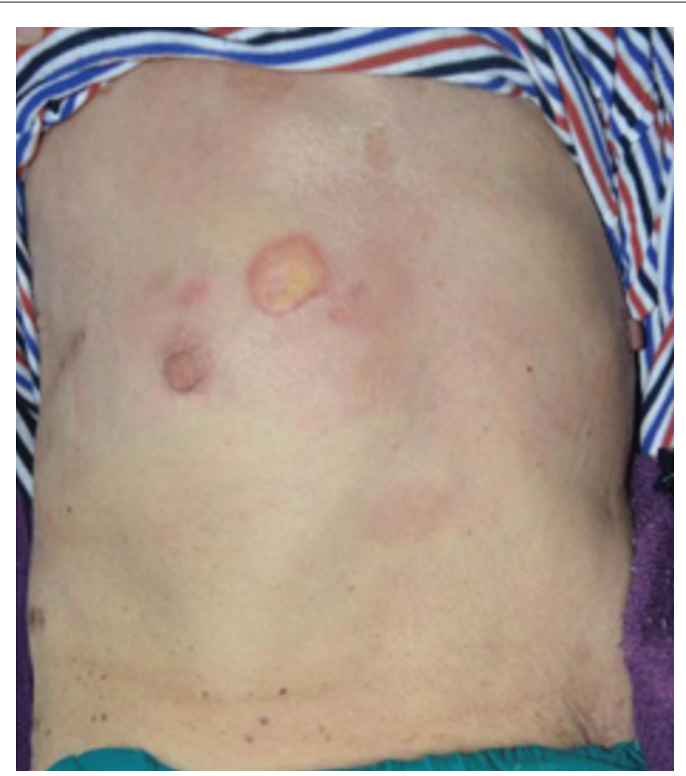

Figure 2: A circular-like infiltrated dark red plaque with a diameter of about $4 \mathrm{~cm}$ can be seen on the right chest, with yellow and white dry secretion in the center.

Combined with clinical manifestations, histopathology, immunohistochemistry and EBV in situ hybridization, the diagnosis was: primary cutaneous extranodal NK/T cell lymphoma (nasal type). After diagnosis, the patient was transferred to the department of oncology radiotherapy and chemotherapy for chemotherapy. After chemotherapy with perenterase, vincristine and methylprednisolone, part of the rash disappeared. Bone marrow suppression after chemotherapy developed 11 days later and the rash continued to improve. At 3 months of follow-up, the rash improved significantly (Figures 14 and 15), but she developed pneumonia and died of respiratory failure.

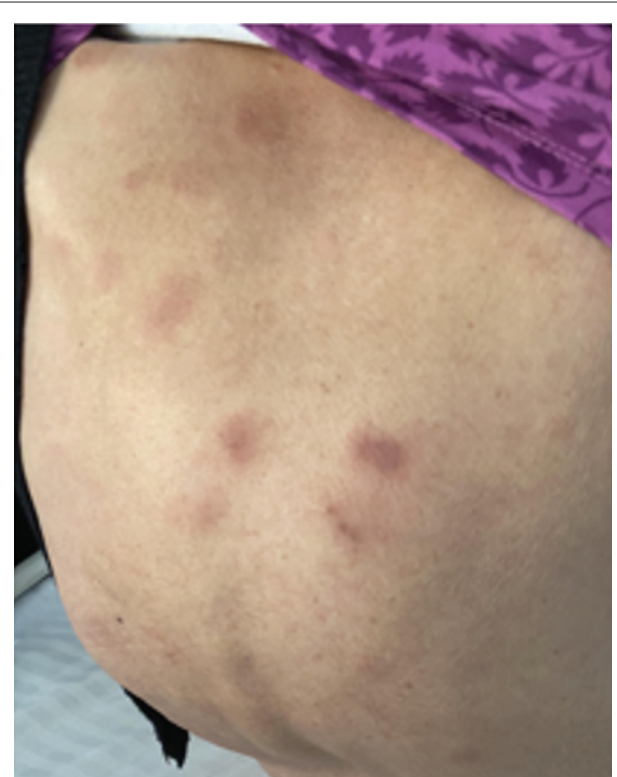

Figure 3: Multiple patches of dark red spots from coins to walnuts can be seen on the trunk and limbs.

\section{Discussion and Conclusion}

Extranodal NK/T cell lymphoma, nasal type (ENKTL-NT) is a rare non-hodgkin's lymphoma, which is highly aggressive. It accounts for about $2 \% \sim 10 \%$ of all malignant lymphomas. Due to the majority of tumor cells expressing NK cell phenotype and the minority expressing cytotoxic T cell marker, this disease is called NK/T cell lymphoma. Enktl-nt is very unevenly distributed throughout the world and is more common in Asia and Central and South America. More than $80 \%$ of this disease occurred in nasopharynx and nasal cavity, and $26 \%$ occurred in skin, which is the most commonly involved extranasal site. When the skin is the primary site, it is called the primary cutaneous extranodal NK/T-cell lymphoma, nasal type (PC-ENK/TNT) [1]. In addition to the primary skin lesions, skin lesions may also be secondary manifestations of the disease. If the midline face is involved first, and then other anatomical lesions appear, it is a secondary or diffuse lesion [2]. Whether the skin lesions were primary or secondary, PC-ENK/T-NT is rare, which accounts for only about $0.3 \% \sim 7.1 \%$ of cutaneous lymphoma [3].

The disease is associated with epstein-barr virus infection of $\mathrm{T}$ cells or NK cells, but the exact mechanism and its role in the pathogenesis of the disease have not been fully deciphered [4]. In recent years, other oncogenic mechanisms have been identified through high-throughput molecular and genomic mapping studies, including platelets-derived growth factor (PDGF), Janus-associated kinases/signal transducers and transcriptional activators (JAK/STAT), aurora kinase, NF- $\kappa$ B, and MYC, and have been identified as potential therapeutic targets [5]. The presence of tumor suppressor genes on chromosome 6Q21 may be associated with the pathogenesis, including HACE1, PRMD1, FOXO3 and PTPRK. In addition to inactivation/deletion of tumor suppressor genes, some oncogene activation may be associated with the pathogenesis of NK/T cell tumor, such as EZH2 and RUNX3 [6].

Extranodal nasal NK/T cell lymphoma has no characteristic skin lesion. And tumor tissue is often necrotic due to the histological characteristics of vascular destruction and coagulative necrosis, which makes clinical biopsy more difficult. Lesions are mostly single or 


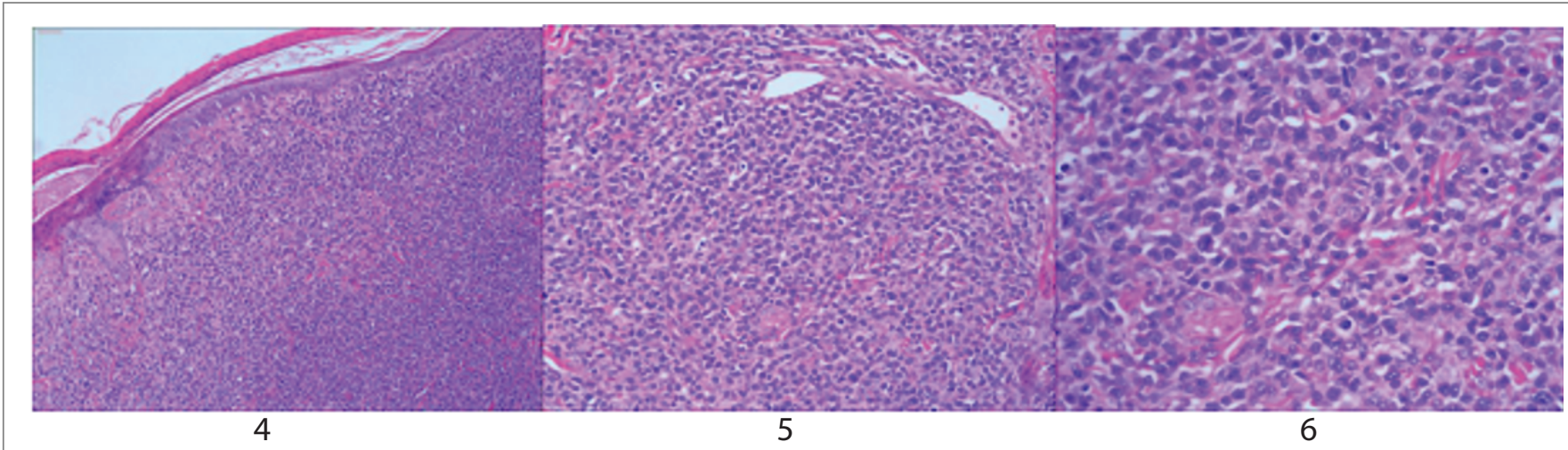

Figure 4-6: The tumor is composed of atypical lymphocytes to a certain extent, with transparent cells, necrosis and mitosis.

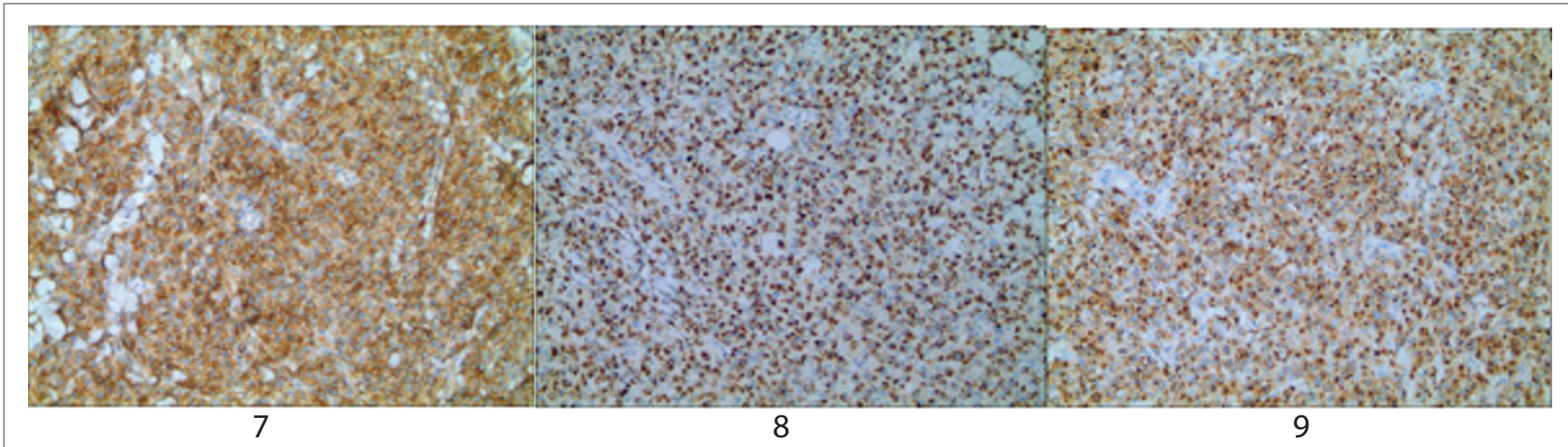

Figure 7-9: Immunohistochemistryy revealed positivity for CD56, TiA-1, granase B.

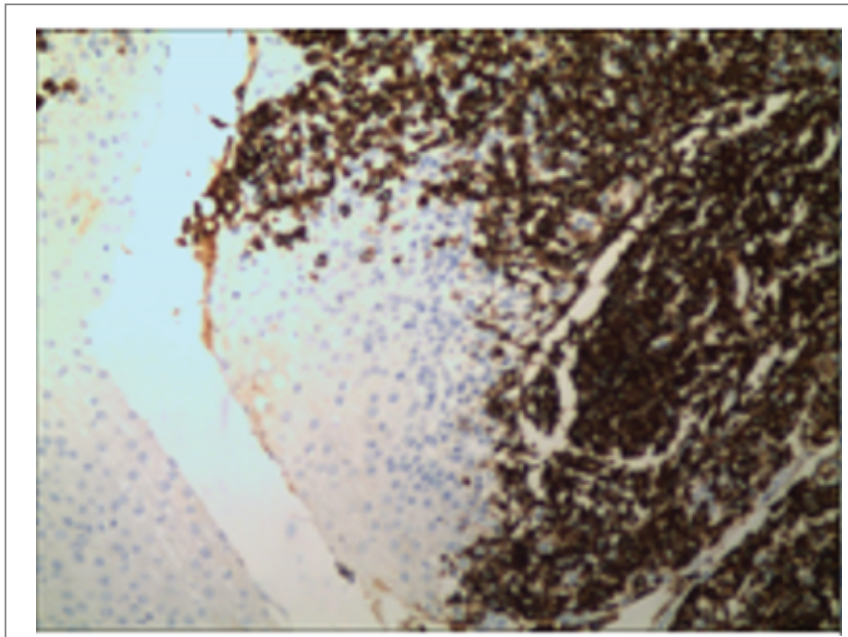

Figure 10: Some cells revealed positivity for CD20.

multiple plaques, nodules, tumors and ulcers, often red or purple. Skin lesions are easily combined with local bacterial or fungal infection resulting in cellulitis, accompanied by fever easily misdiagnosed as infectious dermatosis. The disease can be accompanied by fever, discomfort, weight loss and other systemic symptoms. Hemophagocytic syndrome is also a possible complication of this disease [7].

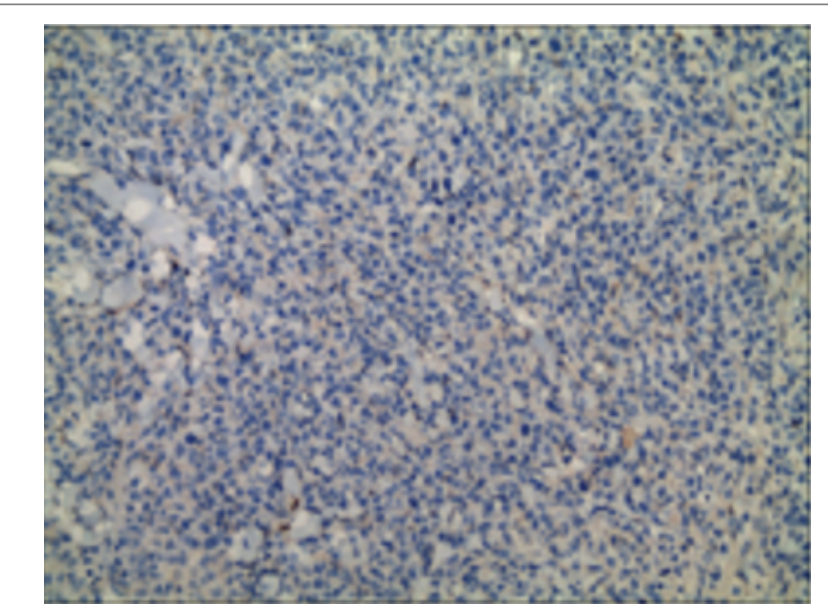

Figure 11: Immunohistochemistry demonstrated negative staining for $\mathrm{CD} 30$.

The initial evaluation of a newly-diagnosed patient includes standard hematological and serum biochemistry profile, PET/CT and plasma EBV DNA quantification to rule out occult primary nasal lymphoma. Marrow trephine biopsy should be performed. With biopsy from bone marrow, we can confirm whether there is invasion to the bone marrow [8]. Random skin biopsy may be useful in early diagnosis, early tumor stage and assessment of prognosis in ENKTL-NT [9].

Citation: Lijie W, Feng J, Qian Z, Hui J, Jie B, et al. (2021) Primary Cutaneous Extranodal NK/T Cell Lymphoma (Nasal Type): A Case Report and Review of Literatures. J Clin Case Stu 6(6): dx.doi.org/10.16966/2471-4925.240 


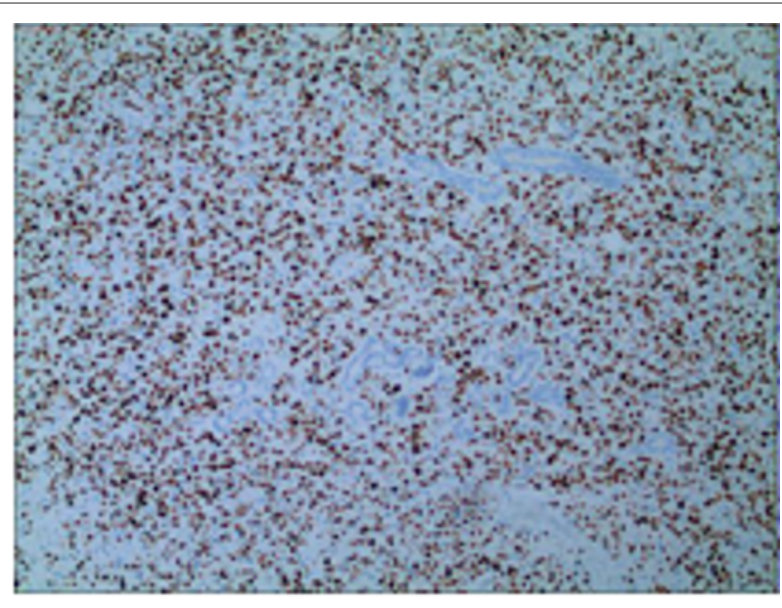

Figure 12: Positive expression of $\mathrm{KI}-67$ in tumor nucleus (index $80 \%)$.

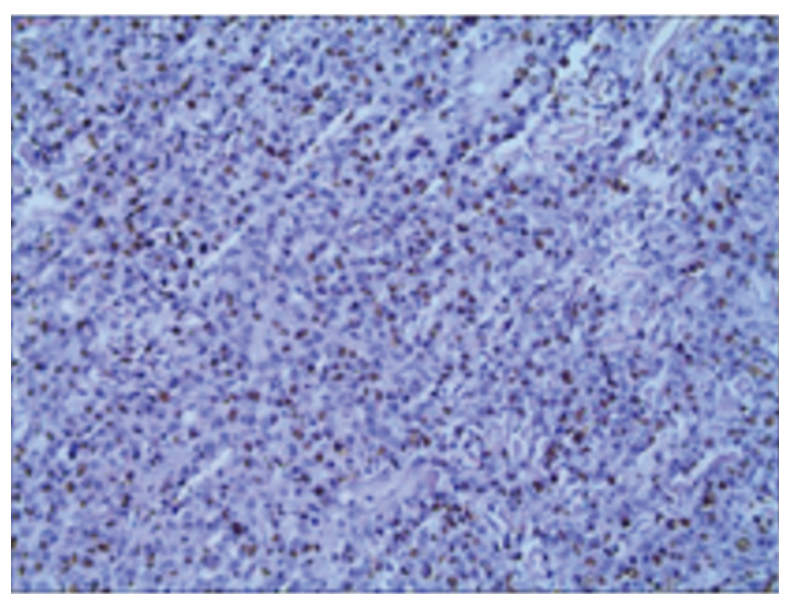

Figure 13: EBER positive tumor cells, in situ hybridization.

Diagnosis of ENKTL-NT depends on the pathological characteristics; immunohistochemical phenotypes and the evidence of Epstein-Barr virus infection. EB virus detection methods include EBER in situ hybridization, EBV immunophenotype, PCR detection of EB virus DNA and detection of EB virus antibody in peripheral blood. At present, the most common and sensitive method is in situ hybridization of EBV-encoded small molecule mRNA (EBER), whose detection rate is better than immunohistochemistry [10]. Studies have shown that peripheral blood EB virus detection has the significance of assisting in the diagnosis of NK / T cell lymphomas and evaluating the prognosis of patients [11], and EBV DNA load before and after treatment can predict short-term efficacy and long-term survival [12]. Histopathology tumor cells have characteristic vascular center growth pattern. Tumor cells infiltrate diffusely into the dermis and subcutaneous tissue, most of which are of moderate size. The tumor cells have irregular nuclei with mitotic patterns. Nucleoli are often inconspicuous, and faintly stained to translucent cytoplasm can be seen. Inflammatory cells such as plasma cells, eosinophils, small lymphocytes and histopathological cells are often found in histopathological manifestations, which mimic benign inflammatory skin disease and are misdiagnosed [13]. At present, no clinicopathological differences between different clinical manifestations have been found, but the possibility of differences cannot be ruled out [14]. Immunohistochemistry is the main diagnostic basis of ENKTL-NT. Tumor cells are bidirectional source of NK cells and T cells. Tumor cells express differentiation antigens of T-cell (CD3 and CD45RO) or differentiation antigen of NK cells (CD56, CD2 and CD36). It can also express cytotoxic proteins such as granzyme b, TIA-1 and perforin [15]. Clonal rearrangement of T cell receptor gene was found in a few cytotoxic T cell-derived patients. Ki67 is a marker to judge the degree of cell proliferation. The expression of Ki-67 index is inconsistent in NK/T cell lymphomas, and patients with high expression of Ki-67 usually have a poor prognosis [16,17].

Patients with cutaneous extranodal NK/T cell lymphoma usually have a survival of 2-15 months and a poor prognosis. A summary of previous reports indicated that patients with primary skin involvement had a better prognosis than those with secondary skin involvement [16], which may be related to the fact that the skin is prone to early skin lesions and can tolerate higher doses of radiotherapy [17]. Factors influencing the prognosis of ENKTL-NT generally include age, stage, lymph node involvement, extra-nasal involvement, B symptom, and elevated LDH level and presentation status. In a recent review, age, treatment strategy and treatment response were found to be independent and significant prognostic factors for cutaneous extranodal NK/T cell lymphoma [18].

Due to the rarity of cutaneous extranodal NK/T cell lymphoma and its clinical histological specificity, most cases are described in case reports or small series of reports, and there is currently no optimal treatment strategy. Extranodal nasal NK/T cell lymphoma is mainly treated with radiotherapy and chemotherapy in the early stage, with chemotherapy the main treatment for advanced ENKTL, and local radiotherapy can be considered for residual lesions. Allogeneic hematopoietic stem cell transplantation is often used as a salvage treatment, and the optimal time is the period when the disease reaches complete remission before transplantation, which is usually used for advanced and refractory/recurrent cases [19].

The patient is an elderly woman with early manifestations of a right shoulder mass, surface ulceration, scattered red plaques on the trunk and limbs, with fever, and with no manifestations on the face. She is in good mental state, with negative EB virus antibodies in peripheral blood, and her lungs at the early stage of onset partial infections can easily be misdiagnosed as infectious skin diseases. No pathogenic bacteria were found in bacterial cultures of secretions, with antiinfective treatments ineffective, and pancytopenia and progressive weight loss occurred. Skin tissue biopsy, immunohistochemistry, EBER in situ hybridization, and bone marrow aspiration were performed to finally support the diagnosis of primary skin extranodal NK/T cell lymphoma (nasal type). The disease is highly malignant. The patient's age, B symptoms, increased LDH, and Ki-67 index of $80 \%$ all indicate a poor prognosis. Due to the age of the patient in this case, there are many underlying diseases. Because the right limb is unfavorable after cerebral infarction, and the skin lesions are scattered, therefore radiotherapy is not available. After chemotherapy, bone marrow suppression occurred after chemotherapy, and the rash continued to improve. However, she died of respiratory failure due to pneumonia during a 3-month followup. This case suggests that infections should not be the only focus on patients with skin necrosis and ulcers, lung infections, and repeated fevers after anti-infective treatment. Active search for the cause should be done and tumors and suspected rapidly progressing diseases should be ruled out. Skin tissue biopsy should be actively performed instead of waiting for the results of other non-invasive tests. Close attention should be paid because the disease progresses quickly. With the low incidence, it is easy to be misdiagnosed in the early stage. 


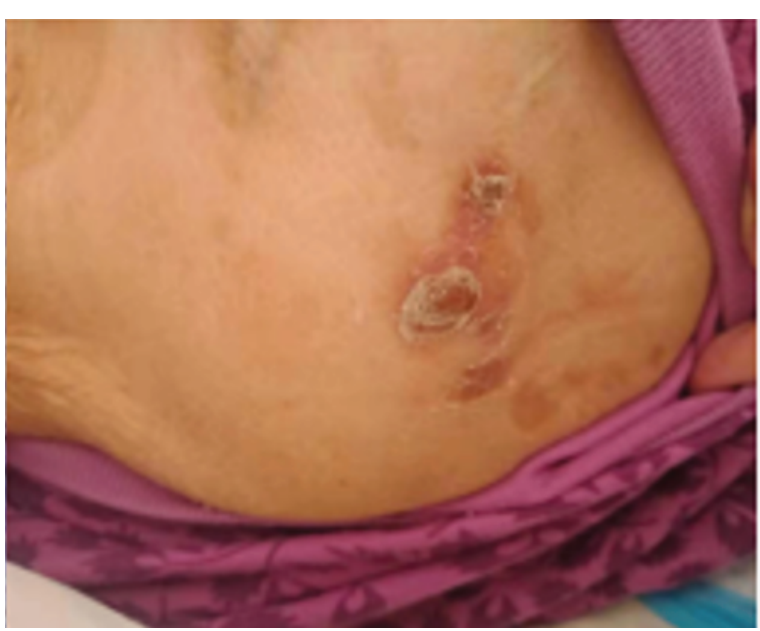

14

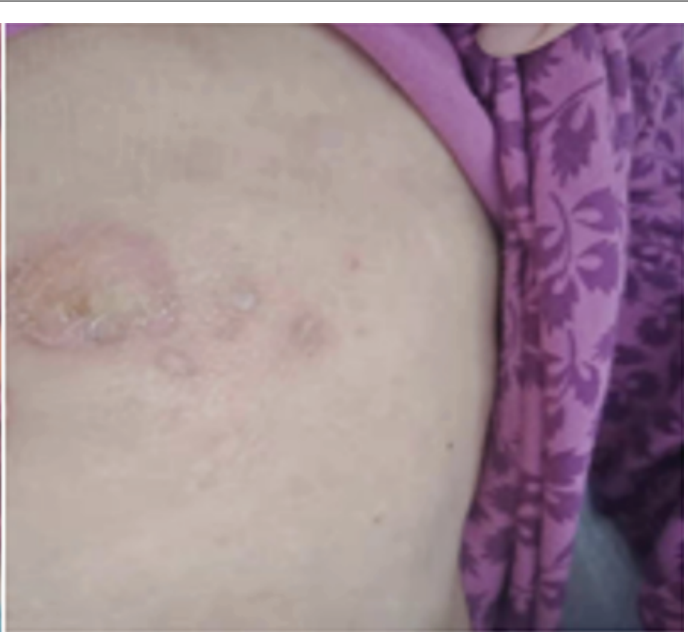

15

Figure 14,15: The rash on the right shoulder and chest was markedly improved.

\section{References}

1. Stout AP, Murray MR (1942) Hemangiopericytoma: A Vascular Tumor Featuring Zimmermann's Pericytes. Ann Surg 116: 26-33.

2. Louis DN, Perry A, Reifenberger G, von Deimling A, Figarella-Branger D, et al. (2016) The 2016 World Health Organization Classification of Tumors of the Central Nervous System: a summary. Acta Neuropathol 131: 803-820.

3. Bai LC, Luo TY, Zhu H, Xu R (2017) MRI features of intracranial anaplastic hemangiopericytoma. Oncol Lett 13: 2945-2948.

4. Begg CF, Garret R (1954) Hemangiopericytoma occurring in the meninges: case report. Cancer 7: 602-606.

5. Jääskeläinen J, Servo A, Haltia M, Wahlström T, Valtonen S (1985) Intracranial hemangiopericytoma: radiology, surgery, radiotherapy, and outcome in 21 patients. Surg Neurol 23: 227-36.

6. Guthrie BL, Ebersold MJ, Scheithauer BW, Shaw EG (1989) Meningeal hemangiopericytoma: histopathological features, treatment, and long-term follow-up of 44 cases. Neurosurgery 25: 514-522.

7. Dufour H, Métellus P, Fuentes S, Murracciole X, Régis J, et al. (2001) Meningeal hemangiopericytoma: a retrospective study of 21 patients with special review of postoperative external radiotherapy. Neurosurgery 48: 756-762.

8. Fountas $\mathrm{KN}$, Kapsalaki $\mathrm{E}$, Kassam $\mathrm{M}$, Feltes $\mathrm{CH}$, Dimopoulos VG, et al. (2006) Management of intracranial meningeal hemangiopericytomas: outcome and experience. Neurosurg Rev 29: 145-153.

9. Wu W, Shi JX, Cheng HL, Wang HD, Hang CH, et al. (2009) Hemangiopericytomas in the central nervous system. J Clin Neurosci 16: 519-523.

10. Zeng L, Wang Y, Wang Y, Han L, Niu HQ, et al. (2017) Analyses of prognosis-related factors of intracranial solitary fibrous tumors and hemangiopericytomas help understand the relationship between the two sorts of tumors. J Neurooncol 131: 153-161.

11. Yamaki VN, de Souza Godoy LF, Bandeira GA, Lucato LT, Lordelo GC, et al. (2021) Dural-based lesions: is it a meningioma? Neuroradiology 63: $1215-1225$
12. Abrahams JM, Forman MS, Lavi E, Goldberg H, Flamm ES (1999) Hemangiopericytoma of the third ventricle. Case report. J Neurosurg 90: 359-362.

13. Sumi K, Watanabe T, Ohta T, Fukushima T, Kano T, et al. (2010) Hemangiopericytoma arising in the body of the lateral ventricle. Acta Neurochir (Wien) 152: 145-149.

14. Avinash KS, Thakar S, Ghosal N, Hegde AS (2016) Anaplastic hemangiopericytoma in the frontal horn of the lateral ventricle. J Clin Neurosci 26: 147-149.

15. Yang $\mathrm{H}$, Zhang $\mathrm{Y}$, Zheng T, Li C, Tang G, et al. (2019) A solitary fibrous tumor/hemangiopericytoma of the fourth ventricle: case report and literature review. J Int Med Res 47: 6349-6355.

16. Mangiardi JR, Flamm ES, Cravioto H, Fisher B (1983) Hemangiopericytoma of the pituitary fossa: case report. Neurosurgery 13: 58-62.

17. Yokota M, Tani E, Maeda Y, Morimura T, Kakudo K, et al. (1985) Acromegaly associated with suprasellar and pulmonary hemangiopericytomas. Case report. J Neurosurg 62: 767-771.

18. Kumar PP, Good RR, Skultety FM, Masih AS, McComb RD (1987) Spinal metastases from pituitary hemangiopericytic meningioma. Am J Clin Oncol 10: 422-428.

19. Kumar PP, Good RR, Leibrock LG, Mawk JR, Yonkers AJ, et al. (1988) High activity iodine 125 endocurietherapy for recurrent skull base tumors. Cancer 61: 1518-1527.

20. Morrison DA, Bibby K (1997) Sellar and suprasellar hemangiopericytoma mimicking pituitary adenoma. Arch Ophthalmol 115: 1201-1203.

21. Gharbi A, Ousehal A, Kissani N, Lakhdar A, Azhari A, et al. (2001) Sellar hemangiopericytoma-Report of a case. J Neuroradiol 28: 195199.

22. Kanda Y, Mase M, Aihara N, Yamada K, Sugino F, et al. (2001) Sellar hemangiopericytoma mimicking pituitary adenoma. Surg Neurol 55: 113-115.

23. Han MH, Cho YD, Kim YD, Kim DH (2007) Recurrent sellar and suprasellar hemangiopericytoma. J Korean Neurosurg Soc 41: 425428. 
24. Juco J, Horvath E, Smyth H, Rotondo F, Kovacs K (2007) Hemangiopericytoma of the sella mimicking pituitary adenoma: case report and review of the literature. Clin Neuropathol 26: 288293.

25. Jalali R, Srinivas C, Nadkarni TD, Rajasekharan P (2008) Suprasellar haemangiopericytoma--challenges in diagnosis and treatment. Acta Neurochir (Wien) 150: 67-71.

26. Das P, Haresh KP, Suri V, Sharma MC, Sharma BS, et al. (2010) Malignant hemangiopericytoma of pituitary fossa. Indian J Pathol Microbiol 53: 109-111.

27. Esquenazi Y, Shank C, Tandon N, Bhattacharjee M (2014) Lipomatous hemangiopericytoma of the sellar region: case report and review of the literature. Ann Clin Lab Sci 44: 104-108.
28. Gibson B, Mancini C, Parker J, Applebaum M, Alatassi H (2017) Sellar and Suprasellar Anaplastic Hemangiopericytoma in a 34-Year Old Man. Ann Clin Lab Sci 47: 349-353.

29. Gunasekaran A, Santos JM, Vandergrift WA $3^{\text {rd }}$ (2020) Supraorbital Craniotomy for Sellar Solitary Fibrous Tumor: Operative Technique and Literature Review. World Neurosurg 141: 395-401.

30. Ma C, Xu F, Xiao YD, Paudel R, Sun Y, et al. (2014) Magnetic resonance imaging of intracranial hemangiopericytoma and correlation with pathological findings. Oncol Lett 8: 2140-2144. 